 \\ z Filologii Polskiej i Słowiańskiej
}

\section{Граматичната категория лице във форумното общуване на bg-mamma}

\section{Въведение}

В последните години изследователи от различни полета на хуманитаристиката, в това число и лингвистите, се включват в изследването на особеностите на компютърно опосредстваната комуникация (КОК) - комуникация, при която компютърът е посредник, който свързва комуникантите. Обичайно вниманието на изследователите езиковеди е привлечено от наличието на диграфия и билингвизъм - още Д. Кристъл (Crystal, 2004, p. 91) споменава, че особеностите на т.нар. от него Netspeak ${ }^{1}$ се откриват преди всичко в лексикона и графологията, защото там найлесно се наблюдават иновациите и отклоненията.

Граматичната система, за разлика от лексикалната, е консервативна и граматичните особености на текстовете не се набиват на очи, както и липсва динамика на процеса. Затова и много рядко граматичните характеристики на

${ }^{1}$ От пеt- мрежа и speak - говоря.

This is an Open Access article distributed under the terms of the Creative Commons Attribution 3.0 PL License (creativecommons.org/licenses/by/3.0/pl/), which permits redistribution, commercial and non-commercial, provided that the article is properly cited. () The Author(s) 2017.

Publisher: Institute of Slavic Studies, Polish Academy of Sciences

[Wydawca: Instytut Slawistyki Polskiej Akademii Nauk] 
различните текстове на КОК са обект на интерес от страна на изследователите на компютърно опосредстваната комуникация. Ето защо и изследванията, доколкото са налични, са частични - ако отново се позовем на Д. Кристъл, то когато се изследват специфични граматични особености, те се отнасят до определена ситуация или група от потребители (Crystal, 2004, p. 91).

Herring (2012, p. 4) също споменава, че много по-рядко се описват морфологичните особености на КОК, като главно се обрыща внимание на някои активни форманти и на някои словообразувателни процеси. Тя посочва, че често описваните процеси не са характерни само за този тип комуникация, но са продуктивни и генерират нови думи, някои от които са характерни за определени контексти и имат игрова функция. Отбелязва също така, че „повече от един морфологичен процес може да оперира с една-единствена дума и неконвенционалната морфология понякога се комбинира с ненормативна типография и/или ортография “2 (Herring, 2012, p. 4). Видно е, че авторката споменава такива граматични характеристики, които засягат процеса на словопроизводство и които имат отношение и към лексикалната система на езика. Словообразувателните процеси в КОК са проучени доста задълбочено (Кирова, 2010, 2012; Тодорова, 2013, 2015a, 2015b, 2016). Същинските граматични характеристики на КОК обаче, както вече казахме, са доста по-слабо проучени - изключение правят изследванията на някои стилистични употреби на категориите лице и число във форумите за майки (Тодорова, 2009), както и на някои синтактични характеристики на комуникацията в политическите блогове (Грозева, 2011) и във форумите за майки (Тодорова, 2015b). Настоящата статия е част от по-мащабно изследване на езика в посветените на родителството интернет форуми, което има амбицията да опише граматическите и лексикалните особености на общуването в тях.

\section{Цел, задачи и обект на изследването}

В това изложение се обръща внимание на един специфичен тип компютърно опосредствана комуникация - тази в най-големия български форум - bg-mamma (www.bg-mamma.com). Форумът е публичен асинхронен жанр с неограничен брой комуниканти, общуването в него е диалогично

2 "More than one morphological process may operate on a single word, and unconventional morphology sometimes combines with unorthodox typography and/or orthography". 
и центрирано върху определена тема, а не върху отделен потребител, както е например в блоговете или социалните мрежи. В конкретния форум, по-точно платформа от форуми, наблюдаваме комуникация с различна степен на неформалност между жени в активна възраст.

Тъй като твърде често се споменава, че въпреки ползването на предимно писмен канал за връзка, компютърно опосредстваната комуникация заема междинно място между устната и писмената комуникация (Davis \& Brewer, 1997; Murray, 2000; Segerstad, 2002; Crystal, 2004; Greiffenstern, 2010; Грозева, 2011 и пр.), би било интересно да се проследи доколко граматичните употреби в КОК имат характеристики, които се приписват на разговорната реч, и доколко такива, които са обичайни за типичната писмена реч. Разбира се, и за писмената, и за устната комуникация са характерни определени черти, които са застъпени в различна степен в текстовете от различните жанрове (Segerstad, 2002, p. 46). Самата КОК не е еднородна и много от характеристиките, които се срещат в блоговете или имейлите, не са типични за чатовете или някои форуми. Нещо повече, най-вероятно дори в рамките на една платформа от форуми, каквато е $b g$-mamma, степента на формалност и неформалност на общуването ще бъде различна, което ще се отрази на граматическите особености на конкретния комуникативен акт (Hewing \& Coffin, 2004, p. 135).

Освен това различните по вид теми предполагат използването на различен доминиращ тип надизреченски единства: повествователни (наративни); описателни (дескриптивни), аргументативни, апелативни (Добрева \& Савова, 2000, р. 116), факт, който не може да не се отрази на използваните езикови средства.

Целта на това изследване е да се проследи предпочитаната употреба на категорията лице във форумите нa bg-mamma, като се използва моделът на Baron (Baron, 1998, p. 153), адаптиран за КОК от Ann Hewing и Caroline Coffin (Hewing \& Coffin, 2004, p. 138). Когато изследват граматичните особености на общуването в дискусионни онлайн групи, авторките изказват хипотезата, че при говоренето по-често се използват първо и второ лице, а при писане - предимно трето лице.

Корпусът на въпросното изследване са общо 450 форумни изказвания, като са ексцерпирани по 150 поста на три различни теми. Първата избрана тема („Искам да кажа ... (45)_13.07-19.07“, 2015) предполага споделяне на лични преживявания и емоции и затова се очаква, че в нея ще се среща твърде често първо лице (това е предпоставено от заглавието ѝ), съответно 
ще преобладават повествователните и по-рядко описателните надизреченски единства. Втората тема („Кое име ви харесва повече? - защо хората питат тук как да си кръстят децата?“, 2015) е дискусия по въпрос, който засяга младите майки, но именно поради полемичния си характер тя се очаква да е по-абстрактна и да бъде по-формална. Тук аргументативните надизреченски единства са преобладаващи. Третата тема („Януарско бебче слънце го напече, зъбче има вече“, 2015-2016) е от т.нар. отчетни $m е м u^{3}$, в които се обсъждат съвсем практически, битови въпроси, тъй като там пишат майки, обединени около еднаквата възраст на децата. Това предполага и най-висока степен на неформалност и разговорност. Срещат се повествователни, по-рядко описателни и апелативни надизреченски единства, аргументативните са най-слабо застъпени.

Ann Hewing и Caroline Coffin проследяват лицето на употребените местоимения в позицията на подлог. В това изследване обаче са разгледани глаголните форми, защото, за разлика от английския език, в български често подлогът се пропуска, особено когато е лично местоимение. Не са изключвани формите, в които подлогът е съществително. Резултатите са изведени в таблици за по-голяма прегледност.

\section{Резултати}

1. Първата изследвана тема е „Искам да кажа ... (45)_13.07-19.07“ (2015) (Таблица 1). Както вече беше споменато, изследвани са първите 150 мнения, изразени с помощта на 6896 думи; формите, които са проследени, са 1128. Средната дължина на всеки пост, написан от отделен потребител, е приблизително 46 думи.

Резултатите сочат, че в 1 л. ед.ч. и 1 л. мн.ч. са общо 526 форми, или около $46 \%$ от всички изследвани употреби в тази тема; във второ лице са общо 90, или около 8 процента от формите; в трето лице са 512, или около $46 \%$ от формите. В ед.ч. са общо 885 форми, или около 78\%, а в мн.ч. са 243 форми, или около $22 \%$.

3 Това са теми, в които пишат потребители, свързани по някакъв признак - найчесто еднаква възраст на децата, но понякога се обединяват около общо хоби, местожителство и пр. Тези теми имат сравнително стабилно ядро от постоянни потребители, някои от които се познават не само виртуално. 


\section{Таблица 1}

\begin{tabular}{|c|c|c|}
\hline Лице, число & Брой & Процент $(\approx)$ \\
\hline 1 л. ед.ч. & 454 & $40 \%$ \\
2 л. ед.ч. & 48 & $4 \%$ \\
3 л. ед.ч. & 383 & $34 \%$ \\
1 л. мн.ч. & 72 & $6 \%$ \\
2 л. мн.ч. & 42 & $4 \%$ \\
3 л. мн.ч. & 129 & $12 \%$ \\
\hline
\end{tabular}

2. От втората тема „Кое име ви харесва повече? - защо хората питат тук как да си кръстят децата?“ (2015) (Таблица 2) също са ексцерпирани първите 150 мнения, изразени с помощта на 7201 думи; общият брой на ексцерпираните форми е 1084. Средната дължина на постовете е от 48 думи.

Таблица 2

\begin{tabular}{|c|c|c|}
\hline Лице, число & Брой & Процент $(\approx)$ \\
\hline 1 л. ед.ч. & 254 & $23 \%$ \\
2 л. ед.ч. & 47 & $4 \%$ \\
3 л. ед.ч. & 497 & $46 \%$ \\
1 л. мн.ч. & 26 & $3 \%$ \\
2 л. мн.ч. & 14 & $1 \%$ \\
3 л. мн.ч. & 246 & $23 \%$ \\
\hline
\end{tabular}

В 1 л. ед.ч. и 1 л. мн.ч. са общо 280 форми - или почти 26\%. Във второ лице ед. и мн.ч. са общо 61 форми, или около 5\% от изследваните форми; в 3 л. ед. и мн.ч. са 743, или почти $69 \%$ от всички изследвани форми. В ед.ч. са около $73 \%$ от глаголните форми; в мн.ч. са около $27 \%$ от тях.

3. Третата изследвана тема е т.нар. отчетна тема в подфорум Родени nрез 2015: „Януарско бебче слънце го напече, зъбче има вече“ (2015-2016) (Таблииа 3). Ексцерпираните 150 мнения са изразени с помощта на 10189 думи, изследваните форми са 1762. Средната дължина на постовете е 68 думи. 
Таблица 3

\begin{tabular}{|c|c|c|}
\hline Лице, число & Брой & Процент ( $)$ \\
\hline 1 л. ед.ч. & 598 & $34 \%$ \\
2 л. ед.ч. & 87 & $5 \%$ \\
3 л. ед.ч. & 752 & $43 \%$ \\
1 л. мн.ч. & 135 & $8 \%$ \\
2 л. мн.ч. & 62 & $3 \%$ \\
3 л. мн.ч. & 128 & $7 \%$ \\
\hline
\end{tabular}

В 1 л. ед. и мн.ч. са общо 733, или около 42\% от изследваните форми; във второ лице са 149, или около $8 \%$ от тях; в 3 л. са 880 форми, или около 50\% от формите. Съответно общо в ед.ч. са 1437 форми - или около 82\%; в мн.ч. са 325 - или около 18\% от изследваните форми.

Ето и сравнителна таблица с резултатите (Таблица 4):

Таблица 4

\begin{tabular}{|c|c|c|c|}
\hline Лице, число & $\begin{array}{c}\text { Искам да } \\
\text { кажа* }\end{array}$ & $\begin{array}{c}\text { "Кое име ви харесва } \\
\text { повече?"...** }\end{array}$ & $\begin{array}{c}\text { Януарско бебче } \\
\text { сльнце го напече...*** }\end{array}$ \\
\hline 1 л.ед.ч. & $40 \%$ & $23 \%$ & $34 \%$ \\
2 л. ед.ч. & $4 \%$ & $4 \%$ & $5 \%$ \\
3 л. ед.ч. & $34 \%$ & $46 \%$ & $43 \%$ \\
1 л. мн.ч. & $6 \%$ & $3 \%$ & $8 \%$ \\
2 л. мн.ч. & $4 \%$ & $1 \%$ & $3 \%$ \\
3 л. мн.ч. & $12 \%$ & $23 \%$ & $7 \%$ \\
\hline
\end{tabular}

* „Искам да кажа ... (45)_13.07-19.07“ (2015).

** „Кое име ви харесва повече? - защо хората питат тук как да си кръстят децата?“ (2015).

*** „Януарско бебче слънце го напече, зъбче има вече“ (2015-2016).

\section{Дискусия}

Изследването посочва някои доста интересни резултати. Както вече бе споменато, смята се, че използването на първо и второ лице е по-характерно за устното общуване, което е диалогично, с честа смяна на ролята на говорещия и слушащия. За писменото общуване е по-харак- 
терно използването на трето лице. Въпреки че това е общата тенденция, все пак и при устната, и при писмената комуникация има различни комуникативни ситуации с различна степен на формалност, при които преобладава употребата на различни типове надизреченски единства. Представяне на факти за трети лица и разказването на събития, в които комуникантите не са преки участници, се срещат и в устното общуване; изповедта и представянето на лични преживявания са характерни за някои писмени жанрове като епистоларните текстове например.

Затова в изследвания корпус са застъпени откъси от форумни дискусии с различна тематика и различни участници. В първата изследвана тема - „Искам да кажа... (45)_13.07-19.07“ (2015), споделянето на лични преживявания е водещо. Затова и употребата на първо лице ед.ч. е по-честа, отколкото в останалите две теми - $40 \%$ срещу $23 \%$ и $34 \%$. В същото време 3 л. също се употребява често - $34 \%$ от употребите в ед.ч. са в трето лице, както и $12 \%$ от употребите в мн.ч., като в крайна сметка общо за двете числа и 1 л., и 3 л. имат около 46\% (526 форми в първо и 512 форми в трето лице) - т.е. резултатите са много близки.

Втората изследвана тема е дискусионна - различни потребители представят позицията си по определен казус. Темата предполага използване на първо лице, тъй като в крайна сметка се изразява лична позиция. От друга страна, дискусиите изискват аргументация, като често аргументите са представени под формата на чужди истории, които подкрепят тезата; на някакви изследвания или журналистически материали. Съответно найчеста е употребата на 3 л. ед.ч. - 46\% от всички изследвани форми са в това лице и число; доста висок е процентът на употребите и в 3 л. мн.ч. - 23\%. Около $69 \%$ от всички изследвани употреби са в 3 л. в двете числа.

В първо лице единствено число са също немалък брой форми - 254 или $23 \%$. Тази честота потвърждава очакването за вербализиране на собствената позиция.

В третата тема, в която се споделят ежедневни битови ситуации и проблеми, отново най-честа употреба има трето лице, ед.ч. - 43\% от формите. Въпреки че тази тема е най-неформална и най-близка до ежедневното общуване, тя отново не е с твърде честа употреба на първо и второ лице. Разбира се, употребата на 3 л. е обяснима - потребителите разказват ежедневни ситуации, свързани с трети лица; обсъждат различни предмети, с които боравят. Те освен това са обединени от общата възраст на децата, което предполага споделяне на бебешкото ежедневие, 
задаване на въпроси за децата на останалите потребителки. Първо лице ед.ч. също има висока честота.

Прави впечатление ниската честота на второ лице и в двете числа във всички изследвани постове. Поради това може да има известно съмнение по отношение на това доколко диалогът в дискусиите е реален и персонифициран. Отношението към другите се изразява по друг начин - както индиректно, чрез споделяне на позиция по вече застъпен от предишен потребител проблем; така и чрез обръщение, чрез цитат и пр.

\section{Изводи}

Количествените данни очертават някои интересни тенденции:

1. Най-дълги са постовете на потребителките, пишещи в отчетната тема „Януарско бебче слънце го напече, зъбче има вече“ (2015-2016) средно с около 20 думи повече, най-кратки са тези в „Искам да кажа ... (45)_13.07-19.07“(2015). В дискусионната тема „Кое име ви харесва повече? защо хората питат тук как да си кръстят децата?“ (2015) дължината на постовете е много близка до тази в „Искам да кажа ... (45)_13.07-19.07“ (2015). Може да се предположи, че в отчетните теми, поради по-близките отношения между комуникантите, които изграждат своя неформална общност, потребителите са по-словоохотливи, когато разказват свои преживявания и коментират чуждо поведение.

2. Много по-честа е употребата на единствено, отколкото на множествено число. Честотата на мн.ч. е малко по-висока в дискусионната тема „Кое име ви харесва повече? - защо хората питат тук как да си кръстят децата?“ (2015), където се обсъждат и чужди казуси с цел доказване на съответна теза. Там трето лице множествено число се употребява толкова често, колкото и 1 л. ед.ч.

3. Трето лице има устойчива честота, като най-ниска е тя в първата тема „Искам да кажа ... (45)_13.07-19.07“ (2015), тъй като там се предполага излагането на лични преживявания и емоции.

4. Активно се употребява и първо лице, като най-ниска е честотата му в дискусионната тема „Кое име ви харесва повече?“- защо хората питат тук как да си кръстят децата?“ (2015), а най-висока в темата, предполагаща споделяне „Искам да кажа ... (45)_13.07-19.07“ (2015). 
5. Въпреки че формата на общуване във форума е диалогична, употребата на второ лице не е особено честа. Диалогичността обичайно се проявява, като части от определени мнения се посочват като цитати, чрез обръщения с никове (псевдоними) и т.н. Прави впечатление фактът, че често, особено при дискусии или сблъсъци на мнения, представянето на различните позиции е индиректно, без явна конфронтация с вече изразените мнения - наблюдение, което се нуждае от по-задълбочено изследване.

Резултатите разкриват, че във форумното общуване се употребява предимно трето лице, което противоречи на очакването, че поради приликите с устното общуване ще се срещат предимно 1 л. и 2 л. Първо лице също е силно застъпено, но пък слабата застъпеност на второ лице не работи в полза на тезата за диалогичността на форумната комуникация. Би било интересно да се направят повече проучвания на предпочитаната употреба на категорията лице в други текстове на КОК. Това би дало много важни отговори на въпроса за разликите между неформалната писмена КОК и неформалната устна комуникация, както и за мястото и ролята на неформалната КОК сред останалите жанрове и форми на писмената комуникация. Поради безпрецедентно широкото разпространение на писмената неформална комуникация тези наблюдения ще дадат ценна информация и за активните развойни процеси в съвременния български език.

Данните разкриват и липсата на еднотипност в неформалната компютърно опосредствана комуникация - различните теми предполагат употребата на различни езикови средства. В зависимост от комуникативната ситуация комуникантите ползват различни стратегии, за да представят преживяванията и тезите си по начин, който би ги представил в добра светлина и би довел до симпатизиране на позицията им. Тъй като общуването в платформата е анонимно, с помощта на псевдоними (никове), възможността потребителите да привлекат вниманието към своето изказване е чрез добър изказ, умение за предаване на факти и преживявания, умела аргументация. По-задълбоченото изследване на езиковите средства - не само лексикални, но и граматични, чрез които общуващите успешно изграждат своите стратегии, би било от голяма полза за комуникативната лингвистика, реториката, прагматиката и други сродни науки. 


\section{Библиография}

Baron, N. (1998). Letters by phone or speech by other means: The linguistics of email. Language and Communication, 18(2), 133-170. https://doi.org/10.1016/S0271-5309(98)00005-6

Crystal, D. (2004). Language and the Internet. Cambridge: Cambridge Univ. Press. https://doi .org/10.1017/CBO9781139164771

Davis, B., \& Brewer, J. (1997). Electronic discourse: Linguistic individuals in virtual space. Albany, NY: State University of New York Press.

Greiffenstern, S. (2010). The influence of computers, the Internet and computer-mediated communication on everyday English. Berlin: Logos Verlag Berlin $\mathrm{GmbH}$.

Herring, S. (2012). Grammar and electronic communication. In C. A. Chapelle (Ed.), Encyclopedia of Applied Linguistics. Hoboken, NJ: Wiley-Blackwell. https://doi.org/10.1002/9781405198431 .wbeal0466

Hewing, A., \& Coffin, C. (2004). Grammar in the construction of online discussion messages. In A. Hewing \& C. Coffin (Eds.), Applying English grammar: Corpus and functional approaches (pp. 134-154). London: Routledge.

Murray, D. (2000). Protean communication: the language of computer-mediated communication. TESOL Quarterly, 34(3), 397-421. https://doi.org/10.2307/3587737

Segerstad, Y. (2002). Use and adaptation of written language to the conditions of computermediated communication. Göteborg: Department of Linguistics. University of Gothenburg, Sweden. http://nl.ijs.si/janes/wp-content/uploads/2014/09/segerstad02.pdf

Грозева, М. (2011). Езикът в интернет. София: ЛСД издателство.

Добрева, Е., \& Савова, И. (2000). Текстолингвистика. Шумен: УИ „К. Преславски“.

Искам да кажа ... (45)_13.07-19.07. (2015). Retrieved 2 June 2017, from http://www.bg-mamma .com/index.php?topic $=858417$

Кирова, Л. (2010). Езикът на BG инфо поколението. София: Галик.

Кирова, Л. (2012, Мау 3). За един модел на сложна номинация, проникнал с турски заемки, и неговото развитие в съвременния български език. Liternet, (№ 5 (150)). Retrieved 2 June 2017, from http://liternet.bg/publish3/lkirova/turski-izafeti.htm

Кое име ви харесва повече? - защо хората питат тук как да си кръстят децата? (2015). Retrieved 2 June 2017, from http://www.bg-mamma.com/index.php?topic=857393

Тодорова, Б. (2009). Стилистични транспозиции на категориите „лице“ и „число“ в речта на форумските майки. In Научни трудове: Филология (Том 47, кн. 1, сб. Б., рp. 238-246). Пловдив: УИ “П. Хилендарски“.

Тодорова, Б. (2013). За някои специфични лексикални употреби във форумите на BG-mamma. In Л. Крумова-Цветкова, Д. Благоева, \& С. Колковска (Eds.), 70 години българска академична лексикография: Сборник доклади от Шестата национална конференция по лексикография и лексикология с международно участие (pp. 438-446). София: АИ „Проф. М. Дринов“.

Тодорова, Б. (2015a). За някои употреби на суфикс - ица във форумите на bg-mamma. In Б. Тодорова \& Г. Падарева-Илиева (Eds.), Лингвистиката: история, предизви- 
кателства, перспективи: Сборник в чест на 80-годишнината на проф. Ив. Кочев (pp. 94-97). Благоевград: УИ „Неофит Рилски“.

Тодорова, Б. (2015b). Лингвистични аспекти на компютьрно опосредстваната комуникация. Благоевград: УИ „Неофит Рилски“.

Тодорова, Б. (2016). За някои специфични употреби на суфикс-че във форумите за майчинство. In Българистични четения, Сегед, 2015 (pp. 321-328). Szeged: JATEPress.

Януарско бебче слънце го напече, зъбче има вече. (2015-2016). Retrieved 2 June 2017, from http://www.bg-mamma.com/index.php?topic $=850578$

\section{Bibliography (transliteration)}

Baron, N. (1998). Letters by phone or speech by other means: The linguistics of email. Language and Communication, 18(2), 133-170. https://doi.org/10.1016/S0271-5309(98)00005-6

Crystal, D. (2004). Language and the Internet. Cambridge: Cambridge Univ. Press. https://doi .org/10.1017/CBO9781139164771

Davis, B., \& Brewer, J. (1997). Electronic discourse: Linguistic individuals in virtual space. Albany, NY: State University of New York Press.

Dobreva, E., \& Savova, I. (2000). Tekstolingvistika. Shumen: UI "K. Preslavski."

Greiffenstern, S. (2010). The influence of computers, the Internet and computer-mediated communication on everyday English. Berlin: Logos Verlag Berlin GmbH.

Grozeva, M. (2011). Ezikǔt v internet. Sofiia: LSD izdatelstvo.

Herring, S. (2012). Grammar and electronic communication. In C. A. Chapelle (Ed.), Encyclopedia of Applied Linguistics. Hoboken, NJ: Wiley-Blackwell. https://doi.org/10.1002/9781405198431 .wbeal0466

Hewing, A., \& Coffin, C. (2004). Grammar in the construction of online discussion messages. In A. Hewing \& C. Coffin (Eds.), Applying English grammar: Corpus and functional approaches (pp. 134-154). London: Routledge.

IAnuarsko bebche slŭntse go napeche, zŭbche ima veche. (2015-2016). Retrieved 2 June 2017, from http://www.bg-mamma.com/index.php?topic $=850578$

Iskam da kazha...(45)_13.07-19.07. (2015). Retrieved 2 June 2017, from http://www.bg-mamma .com/index.php?topic $=858417$

Kirova, L. (2010). Ezikǔt na BG info pokolenieto. Sofia: Galik.

Kirova, L. (2012, May 3). Za edin model na slozhna nominatsiia, proniknal s turski zaemki, i negovoto razvitie v sǔvremenniia bǔlgarski ezik. Liternet, (№ 5 (150)). Retrieved 2 June 2017, from http://liternet.bg/publish3/lkirova/turski-izafeti.htm

Koe ime vi kharesva poveche? - zashto khorata pitat tuk kak da si krŭstiat detsata? (2015). Retrieved 2 June 2017, from http://www.bg-mamma.com/index.php?topic $=857393$

Murray, D. (2000). Protean communication: the language of computer-mediated communication. TESOL Quarterly, 34(3), 397-421. https://doi.org/10.2307/3587737 
Segerstad, Y. (2002). Use and adaptation of written language to the conditions of computermediated communication. Göteborg: Department of Linguistics. University of Gothenburg, Sweden. http://nl.ijs.si/janes/wp-content/uploads/2014/09/segerstad02.pdf

Todorova, B. (2009). Stilistichni transpozitsii na kategoriite "litse" i "chislo" v rechta na forumskite maĭki. In Nauchni trudove: Filologiia (Tom 47, kn. 1, sb. B., pp. 238-246). Plovdiv: UI "P. Khilendarski."

Todorova, B. (2013). Za niakoi spetsifichni leksikalni upotrebi vǔv forumite na BG-mamma. In L. Krumova-TSvetkova, D. Blagoeva, \& S. Kolkovska (Eds.), 70 godini bǔlgarska akademichna leksikografiia: Sbornik dokladi ot Shestata natsionalna konferentsiia po leksikografiia i leksikologiia s mezhdunarodno uchastie (pp. 438-446). Sofia: AI "Prof. M. Drinov."

Todorova, B. (2015a). Za niakoi upotrebi na sufiks -itsa vǔv forumite na bg-mamma. In B. Todorova \& G. Padareva-Ilieva (Eds.), Lingvistikata: Istoriia, predizvikatelstva, perspektivi: Sbornik $v$ chest na 80-godishninata na prof. Iv. Kochev (pp. 94-97). Blagoevgrad: UI "Neofit Rilski."

Todorova, B. (2015b). Lingvistichni aspekti na kompiutǔrno oposredstvanata komunikatsiia. Blagoevgrad: UI "Neofit Rilski."

Todorova, B. (2016). Za niakoi spetsifichni upotrebi na sufiks -che vǔv forumite za maĭchinstvo. In Bǔlgaristichni cheteniia, Seged, 2015 (pp. 321-328). Szeged: JATEPress.

\section{The grammatical category of the person in bg-mamma forum communication}

\section{Summary}

The main purpose of the paper is to present some grammatical features of computer-mediated communication (CMC), in particular the verb category of the person. The specifics of grammar use in CMC texts are not preferred by researchers as they are more difficult to investigate. The grammatical system is more stable and conservative and the differences in grammar use are less discernable.

A lot of investigators claim that CMC occupies the middle position between speech and writing. Hewing and Coffin (2004) consider that in speech the first and the second person use is preferred; in writing the third person has more frequent use. This research thus aims to investigate the use of personal forms of verbs in some discussions in the largest Bulgarian forum platform - bg-mamma. The results show that in the corpus the third person appears more often than others. The second person has lowest use. 


\section{Gramatyczna kategoria osoby w komunikacji na forum internetowym bg-mamma}

\section{Streszczenie}

Podstawowym celem artykułu jest przedstawienie pewnych gramatycznych właściwości komunikacji zapośredniczonej komputerowo (computer-mediated communication, CMC), tyczących się zwłaszcza czasownikowej kategorii osoby. Specyfika gramatyki tekstów CMC nie należy do tematów często podejmowanych przez badaczy, teksty te należą bowiem do trudniej poddających się analizie. System gramatyczny jest tu bardziej stabilny i charakteryzuje się większym konserwatyzmem, co utrudnia notowanie różnic gramatycznych.

Wielu badaczy postuluje, że CMC plasuje się w połowie drogi między mową a pismem. Hewing i Coffin uważają, że w mowie częściej używa się pierwszej i drugiej osoby, w piśmie zaś - trzeciej. Wychodząc z tego założenia, podjęto analizę użycia form osobowych czasowników w niektórych wątkach dyskusyjnych największego bułgarskiego forum internetowego bg-mamma. Jej wyniki wskazują, że w korpusie najczęściej występują czasowniki w trzeciej osobie, najrzadziej zaś - czasowniki w drugiej osobie.

Keywords: computer-mediated communication (CMC); speech; writing; grammatical category of the person in verbs

Słowa kluczowe: komunikacja zapośredniczona komputerowo (CMC); mowa; pismo; czasownikowa kategoria gramatyczna osoby

\footnotetext{
Biliana Todorova, Department of Bulgarian Language, Faculty of Philology, South-West University "Neofit Rilski," Blagoevgrad

Correspodence: bilyanatodorova@swu.bg

This article was financed within the statutory activities of the Department of Bulgarian Language, Faculty of Philology, South-West University "Neofit Rilski."

Competing interest: The author has declared she has no competing interests.
} 